\title{
REVIEW
}

\section{The impact of cleft lip and palate repair on maxillofacial growth}

\author{
Bing Shi ${ }^{1}$ and Joseph E Losee ${ }^{2}$
}

Surgical correction is central to current team-approached cleft treatment. Cleft surgeons are always concerned about the impact of their surgical maneuver on the growth of the maxilla. Hypoplastic maxilla, concaved mid-face and deformed dental arch have constantly been reported after cleft treatments. It is very hard to completely circumvent these postoperative complications by current surgical protocols. In this paper, we discussed the factors that inhibit the maxillofacial growth on cleft patients. These factors included pre-surgical intervention, the timing of cleft palate and alveolae repair, surgical design and treatment protocol. Also, we made a review about the influence on the maxillary growth in un-operated cleft patients. On the basis of previous researches, we can conclude that most of scholars express identity of views in these aspects: early palatoplasty lead to maxilla growth inhibition in all dimensions; secondary alveolar bone graft had no influence on maxilla sagittal growth; cleft lip repair inhibited maxilla sagittal length in patients with cleft lip and palate; Veau's pushback palatoplasty and Langenbeck's palatoplasty with relaxing incisions were most detrimental to growth; Furlow palatoplasty showed little detrimental effect on maxilla growth; timing of hard palate closure, instead of the sequence of hard or soft palate repair, determined the postoperative growth. Still, scholars hold controversial viewpoints in some issues, for example, un-operated clefts have normal growth potential or not, pre-surgical intervention and pharyngoplasty inhibited maxillofacial growth or not.

International Journal of Oral Science (2014) 7, 14-17; doi:10.1038/ijos.2014.59; published 14 November 2014

Keywords: cleft; growth; maxilla; surgical repair

\section{INTRODUCTION}

Surgical correction is central to the current team approach to cleft treatment. An ideal surgical design should proficiently restore functions including speech, mastication, breathing and aesthetics, while at the same time preserving the normal growth potential in the involved area. Unfortunately, however, hypoplastic maxilla, concaved mid-face and deformed dental arch are consistently reported after surgery, and no currently available surgical protocol can completely circumvent these postoperative complications. ${ }^{1-4} \mathrm{Up}$-to-date studies concerning the extent and mechanism of surgery-related growth inhibition are reviewed here.

\section{MAXILLARY GROWTH IN UN-OPERATED CLEFT PATIENTS}

Patients with un-operated cleft palate demonstrate reduced maxillary length and retruded premaxillary position relative to the cranial base, ${ }^{5-10}$ which become increasingly obvious as the patients grow. ${ }^{7-8}$ In a study of 39 un-operated cleft palate cases from West China Stomatology Hospital, we observed reduced sagittal length and retruded position of the maxilla at the end of the growth period. ${ }^{11}$ Most un-operated cleft lip patients with or without alveolar involvement demonstrate normal facial projection, exhibiting only dental arch malalignment in the cleft region. ${ }^{9,12-15}$ In the case of un-operated unilateral cleft lip and palate, the maxilla demonstrates normal growth potential in the sagittal dimension, although the dental arch is typically straighter. ${ }^{16-17}$ By studying 24 un-operated unilateral complete cleft lip and palate patients, Capelozza Júnior et al. ${ }^{18}$ suggested that the position and growth amount of these cleft maxillae were similar to normal controls and that the dental arch was normal on the non-cleft side but collapsed medially on the cleft side. These authors further compared the maxillofacial growth of all types of un-operated clefts and found that un-operated cleft lip and alveolus patients demonstrated greater premaxillary projection, maxillary length (Ans-Ptm), labial tipping of the anterior teeth, ANB angle, and maxillary projection (NAPA) with normal mandibular position and dimensions. In another study, un-operated unilateral cleft lip and palate patients demonstrated similar or even more protruded maxillary growth when compared to normal controls. ${ }^{19}$ These finding suggest that unoperated cleft patients possess the normal potential and mechanism for growth.

\section{THE IMPACT OF PRE-SURGICAL INTERVENTION ON MAXILLARY GROWTH}

Currently, pre-surgical nasal alveolar moulding (PNAM) is the most widely used orthopaedic technique for cleft correction. The alar

\footnotetext{
${ }^{1}$ State Key Laboratory of Oral Diseases, Department of Cleft Lip and Palate Surgery, West China Hospital of Stomatology, Sichuan University, Chengdu, China and ${ }^{2}$ University CleftCraniofacial Center, Division of Pediatric Plastic Surgery, Children's Hospital of Pittsburgh, Pittsburgh, USA

Correspondence: Dr B Shi, State Key Laboratory of Oral Diseases, Department of Cleft Lip and Palate Surgery, West China Hospital of Stomatology, Sichuan University, No.14, Section 3, Renmin South Road, Chengdu 610041, China
}

E-mail: shibingcn@vip.sina.com

Accepted 28 September 2014 
cartilage is more pliable to the orthopaedic manoeuvre soon after birth, whereas by the age of 3 months, the cartilage becomes rigid with reduced plasticity. ${ }^{20}$ PNAM can significantly improve the nasal symmetry, elongate the columella, bolster the alae, ${ }^{21-22}$ narrow the cleft and restore the arch form, demonstrating favourable immediate- ${ }^{23}$ and long-term ${ }^{24-25}$ outcomes.

In a follow-up study over 6-9 years, Bennum et al. ${ }^{26}$ found that patients who were treated with PNAM within 15 days after birth all maintained satisfactory nasal symmetry, requiring no further revision. $^{20}$ Ezzat et al. $^{27}$ compared measurements from 12 unilateral cleft lip and palate patients before and immediately after PNAM treatment and found that PNAM narrowed the alveolar cleft, increased the posterior width of the dental arch, uprighted the columella and improved the nasal symmetry. In particular, the increase in the height of the cleft side nostril was closely related to the PNAM treatment. Yang et al. ${ }^{28}$ reported similar results from 45 unilateral complete cleft lip and palate patients. Moreover, it was reported that $60 \%$ of cleft alveolus patients treated with PNAM did not require secondary bone grafting, and early restoration of the dental arch facilitated normal facial growth. ${ }^{29}$

PNAM devices developed for bilateral clefts can hold back the protruded premaxillae, reduce the alveolar gap and non-surgically elongate the columella. ${ }^{30}$

In a large multicentre study sample, Ross ${ }^{31}$ concluded that orthopaedic correction of the premaxillae failed to stimulate maxillary growth, and thus was not necessary, and that the reduction of the cleft was due to the transverse growth of the maxillae. In contrast, Ras et al. $^{32}$ considered distraction forces that may disturb the growth centre in the premaxillae and interfere with midfacial growth.

\section{SURGICAL TIMING AND MAXILLOFACIAL GROWTH}

\section{The timing of cleft palate repair}

In a large sample study including over 2000 cases, Koberg and Koblin $^{33}$ reported similar postoperative maxillary growth rates among patients who took either early ( $<1$ year old) or delayed palatoplasty, and most of the observed midfacial retrusion occurred between 8 and 15 years of age. However, this surgery should generally be postponed until 15 years of age in order to completely avoid growth interference, including impacts on speech development and sociopsychological health. Early palatoplasty produces maximal growth inhibition in all dimensions, and the surgical region has been shown to grow more slowly than the surrounding tissue. In particular, the severity of growth inhibition is positively related to the timing of surgery and the extent of scar contracture. ${ }^{34}$

\section{The timing of cleft alveolar repair}

Initially, Ross considered the alveolar bone graft procedure to be harmless to maxillary growth because the grafting area was not a growth site. However, in his follow-up large-sample, multicentre study, he found that cleft alveolar repair resulted in reduced maxillary height. ${ }^{35}$ Thus, Ross ${ }^{35}$ proposed postponing cleft alveolar repair until after 9 years of age.

By the 1970s, secondary bone grafting had been accepted by most surgeons for correction of the alveolar cleft. The best timing for this procedure is approximately $9-11$ years of age, at which time the root of the permanent canine has formed $1 / 3$ to $2 / 3$ and the crown is still partially covered by bone. ${ }^{36-38}$ In a cephalometric study, Gesch et al. $^{39}$ suggested that secondary bone grafting has no influence on sagittal growth of the maxillae. Levitt et al. ${ }^{40}$ reported that maxillae tended to retrude after alveolar bone grafting, although such trends existed prior to the bone graft and did not change significantly after the secondary bone graft.

\section{SURGICAL DESIGN AND MAXILLOFACIAL GROWTH}

\section{Cleft lip repair}

In a comparison of 84 cleft lip patients (with or without cleft palate) and normal controls, we found that the extent of growth inhibition after primary lip repair was related to the severity of the original deformities. ${ }^{41}$ Among patients with cleft lip and alveolus, the influence of primary cheiloplasty was mainly restricted to the incisors and alveolus in the cleft site, and the shape and position of the maxillae were similar to those of controls. However, in the case of cleft lip and palate, maxillary retrusion and reduced maxillary length were observed after primary lip repair, whether the cleft palate was repaired or not. Thus, we inferred that the severity of the original defect and displacement of the cleft maxillae was associated with more significant growth inhibition after primary cheiloplasty.

In animal models, we found that both Millard and Tennison lip repairs produced shorter, wider, and posteriorly displaced maxillae, and Tennison's technique tended to cause more problems to the anterior tooth and alveolus. ${ }^{42}$

Shortly after bilateral cleft lip repair, the protruded premaxillae move backwards very rapidly and reach a normal position by adulthood. ${ }^{43}$ The posterior part of the maxillae is somewhat retruded but shows normal dimensions. ${ }^{44}$ Specifically, this moulding effect is a result of the lip pressure from suturing bilateral lateral labial components to the middle. Secondary alveolar deformities due to inappropriate lip pressure may be extremely difficult to correct.

\section{Cleft palate repair}

Koberg and Koblin ${ }^{33}$ closely examined the maxillofacial growth of 1033 cleft palate patients and found that Veau's pushback technique and Langenbeck's technique with relaxing incisions were most detrimental to growth. ${ }^{33}$ Pichler introduced the vomer flap into cleft palate repair in 1926 (ref. 45) but reported a high incidence of premaxillary retrusion, ${ }^{46-47}$ which was avoided when the flap elevation area was restricted away from the vomeropremaxillary suture. ${ }^{48-49}$

In a large-sample, multicentre study in 1987, Ross ${ }^{50}$ found that repairing the soft palate only resulted in decreased posterior maxillary height but normal sagittal length and position of the maxillae. In addition, he suggested that the technique used for soft palate repair was unrelated to maxillary growth. ${ }^{50}$

In 2013, Jackson et al. ${ }^{51}$ examined 1500 patients treated with Furlow palatoplasty and reported no significant midfacial retrusion or crossbite; only $14 \%$ patients in this study required LeFort I advancement. In another consecutive series of 33 double- $Z$ palatoplastytreated patients from Florida, only 1 bilateral case required maxillary advancement. ${ }^{52}$

Chate et al. ${ }^{53}$ reported that patients treated with his intravelar palatoplasty without lateral relaxing incisions demonstrated more favourable maxillary growth when compared to European data.

\section{Pharyngoplasty}

Currently, data discussing the relationship between pharyngoplasty and growth remain limited. Long et al. ${ }^{54}$ found that patients who underwent pharyngoplasty between the ages of 5-7 years demonstrated increased lower facial height, posteriorly inferiorly rotated mandibles and lingually tilted incisors. Voshol et al. ${ }^{55}$ studied 580 fully developed cleft patients and found that $19 \%$ of those who underwent pharyngoplasty required LeFort I surgery, while this percentage 
among those who did not undergo pharyngoplasty was only $8 \%$. In contrast, in a series of 48 cleft palate only patients, Heliövaara et al. ${ }^{56}$ found no significant difference in maxillofacial growth between patients who received pharyngoplasty and those who did not.

\section{TREATMENT PROTOCOL AND MAXILLOFACIAL GROWTH}

Schweckendiek first proposed repairing the soft palate first and delaying the hard palate closure. After modifications over half a century, this protocol has achieved satisfactory results in preventing growth inhibition. In Schweckendiek's 25-year follow-up study, over $60 \%$ of his patients demonstrated normal maxillary growth, ${ }^{57}$ and Olin reproduced Schweckendiek's success. ${ }^{58}$ The Zürich centre (hard palate closure at 7 years) ${ }^{59}$ and the Göteborg centre (hard palate closure at 9 years $)^{60}$ both achieved satisfactory facial growth using their modified two-stage palate repair protocols.

In 1991, Semb ${ }^{61}$ evaluated another two-stage protocol, the Oslo protocol, in which hard palate closure was performed at the same time as lip repair at 3 months, and then the soft palate was repaired at 18 months. He found that patients treated this way tended to have retruded maxillae and mandibles and reduced posterior facial height. In contrast, Mølsted et al. ${ }^{62}$ found that the Oslo protocol produced the most favourable maxillofacial contour in comparison to other Eurocleft centres. del Guercio et al. ${ }^{63}$ compared patients from Oslo and Milan (where lip repair and soft palate closure were performed at 4-6 months, and hard palate repair and gingivoperiostoplasty were performed together at 18-36 months) and found no difference in maxillofacial growth at 5 years of age.

In a 5-year study, we found that early soft palate closure significantly reduced the width of the hard palate cleft, but did not reduce the final growth inhibition. In addition, sagittal and vertical growth inhibition was similar between one-stage and two-stage treated patients.

This result suggested that it was the timing of hard palate closure, instead of the sequence of hard or soft palate repair, that determined the postoperative growth. ${ }^{64}$ Data from both Mommaerts et al. ${ }^{65}$ and Richard et al. ${ }^{66}$ further support this statement, as these authors found that one-stage and two-stage protocols showed no difference in postoperative maxillary growth because the hard palate was repaired at the same time in both protocols.

1 Hayashi I, Sakuda M, Takimoto K et al. Craniofacial growth in complete unilateral cleft lip and palate: a roentgeno-cephalometric study. Cleft Palate J 1976; 13: 215-237.

2 Hotz MM, Gnoinski WM. Effects of early maxillary orthopaedics in coordination with delayed surgery for cleft lip and palate. J Maxillofac Surg 1979; 7(3): 201-210.

3 Friede $\mathrm{H}$. Growth sites and growth mechanisms at risk in cleft lip and palate. Acta Odontol Scand 1998; 56(6): 346-351.

4 Normando AD, da Silva Filho OG, Capelozza Filho L. Influence of surgery on maxillary growth in cleft lip and/or palate patients. J Craniomaxillofac Surg 1992; 20(3): 111118.

5 Graber TM. The congenital cleft palate deformity. J Am Dent Assoc 1954, 48(4): 375395.

6 Jolleys A. A review of the results of operations on cleft palates with reference to maxillary growth and speech function. Br J Plast Surg 1954; 7(3): 229-241.

7 Osborne HA. A serial cephalometric analysis of facial growth in adolescent cleft palate subjects. Angle Orthod 1966; 36(3): 211-223.

8 Shibasaki Y, Ross RB. Facial growth in children with isolated cleft palate. Cleft Palate J 1969; 6: 290-302.

9 Dahl E. Craniofacial morphology in congenital clefts of the lip and palate. An x-ray cephalometric study of young adult males. Acta Odontol Scand 1970; 28 (Suppl 57): $11+$.

10 Bishara SE, Iversen WW. Cephalometric comparisons on the cranial base and face in individuals with isolated clefts of the palate. Cleft Palate J 1974; 11: 162-175.

11 Ye ZT, Xu X, Ahmatjian A et al. The craniofacial morphology adult patients with unoperated isolated cleft palate. Bone Res 2013; 1(2): 195-200.

12 Harvold E. Cleft lip and palate: morphologic studies of the facial skeleton. Am J Orthod 1954; 40: 493-506.
13 Coupe TB. A study of the morphology and growth of the nasal septum in children with clefts of the lip and palate. Toronto: University of Toronto, 1962.

14 Graber TM. A study of craniofacial growth and development in the cleft palate child from birth to six years of age//Hotz R ed. Early treatment of cleft lip and palate. Bern: Hans Huber, 1964: 30-43.

15 Ross RB, Coupe TB. Craniofacial morphology in six pairs of monozygotic twins discordant for cleft lip and palate. J Can Dent Assoc (Tor) 1965; 31: 149-157.

16 Mars M, Houston WJ. A preliminary study of facial growth and morphology in unoperated male unilateral cleft lip and palate subjects over 13 years of age. Cleft Palate J 1990; 27(1): 7-10.

17 Capelozza Júnior L, Taniguchi SM, da Silva Júnior OG. Craniofacial morphology of adult unoperated complete unilateral cleft lip and palate patients. Cleft Palate Craniofac J 1993; 30(4): 376-381.

18 Capelozza Júnior L, Taniguchi SM, da Silva Júnior OG. Craniofacial morphology of adult unoperated complete unilateral cleft lip and palate patients. Cleft Palate Craniofac J 1993; 30(4): 376-381.

19 Bishara SE, Krause CJ, Olin WH et al. Facial and dental relationships of individuals with unoperated clefts of the lip and/or palate. Cleft Palate J 1976; 13: 238-252.

20 Matsuo K, Hirose T. Preoperative non-surgical over-correction of cleft lip nasal deformity. Br J Plast Surg 1991; 44(1): 5-11.

21 Grayson $\mathrm{BH}$, Santiago PE, Brecht LE et al. Presurgical nasoalveolar molding in infants with cleft lip and palate. Cleft Palate Craniofac J 1999; 36(6): 486-498.

22 Grayson BH, Cutting CB. Presurgical nasoalveolar orthopedic molding in primary correction of the nose, lip, and alveolus of infants born with unilateral and bilateral clefts. Cleft Palate Craniofac J 2001; 38(3): 193-198.

23 Pai BC, Ko EW, Huang CS et al. Symmetry of the nose after presurgical nasoalveolar molding in infants with unilateral cleft lip and palate: a preliminary study. Cleft Palate Craniofac J 2005; 42(6): 658-663.

24 Liou EJ, Subramanian M, Chen PK et al. The progressive changes of nasal symmetry and growth after nasoalveolar molding: a three-year follow-up study. Plast Reconstr Surg 2004; 114(4): 858-864.

25 Maull DJ, Grayson BH, Cutting CB et al. Long-term effects of nasoalveolar molding on three-dimensional nasal shape in unilateral clefts. Cleft Palate Craniofac J 1999; 36(5): 391-397.

26 Bennun RD, Perandones C, Sepliarsky VA et al. Nonsurgical correction of nasal deformity in unilateral complete cleft lip: a 6-year follow-up. Plast Reconstr Surg 1999; 104(3): 616-630.

27 Ezzat CF, Chavarria C, Teichgraeber JF et al. Presurgical nasoalveolar molding therapy for the treatment of unilateral cleft lip and palate: a preliminary study. Cleft Palate Craniofac J 2007; 44(1): 8-12.

28 Yang C, Huang N, Shi B. [Clinical research of presurgical orthodontic treatment of complete cleft lip and palate infant.] Hua Xi Kou Qiang Yi Xue Za Zhi 2011; 29(4): 396-399. Chinese.

29 Santiago PE, Grayson BH, Cutting CB et al. Reduced need for alveolar bone grafting by presurgical orthopedics and primary gingivoperiosteoplasty. Cleft Palate Craniofac 1998; 35(1): 77-80.

30 Wood RJ, Grayson BH, Cutting CB. Gingivoperiosteoplasty and midfacial growth. Cleft Palate Craniofac J 1997; 34(1): 17-20.

31 Ross RB. Growth of the facial skeleton following the Malek repair for unilateral cleft lip and palate. Cleft Palate Craniofac J 1995; 32(3): 194-198.

32 Ras F, Habets LL, van Ginkel FC et al. Longitudinal study on three-dimensional changes of facial asymmetry in children between 4 to 12 years of age with unilateral cleft lip and palate. Cleft Palate Craniofac J 1995; 32(6): 463-468.

33 Koberg W, Koblin I. Speech development and maxillary growth in relation to technique and timing of palatoplasty. J Maxillofac Surg 1973; 1(1): 44-50.

34 Graber TM. Changing philosophies in cleft palate management. J Pediatr 1950; 37(3): 400-415.

35 Ross RB. Treatment variables affecting facial growth in complete unilateral cleft lip and palate. Cleft Palate J 1987; 24(1): 5-77.

36 Pirruccello FW. Cleft lip and palate. Springfield: Chareles C Thomas Publisher, 1987: 9.

37 Samman N, Cheung LK, Tideman H. A comparison of alveolar bone grafting with and without simultaneous maxillary osteotomies in cleft palate patients. Int J Oral Maxillofac Surg 1994; 23(2): 65-70.

38 Bergland O, Semb G, Abyholm FE. Elimination of the residual alveolar cleft by secondary bone grafting and subsequent orthodontic treatment. Cleft Palate 1986; 23(3): 175-205.

39 Gesch D, Kirbschus A, Mack F et al. Comparison of craniofacial morphology in patients with unilateral cleft lip, alveolus and palate with and without secondary osteoplasty. J Craniomaxillofac Surg 2006; 34(Suppl 2): 62-66.

40 Levitt T, Long RE Jr, Trotman CA. Maxillary growth in patients with clefts following secondary alveolar bone grafting. Cleft Palate Craniofac J 1999; 36(5): 398-406.

41 Li Y, Shi B, Song QG et al. Effects of lip repair on maxillary growth and facial soft tissue development in patients with a complete unilateral cleft of lip, alveolus and palate. J Craniomaxillofac Surg 2006; 34(6): 355-361.

42 Meng $T$, Shi $B$, Wang $Q$ et al. A comparative study of maxillary growth following rotation-advancement and triangular flap unilateral cleft lip repairs: an experimental study in rabbits. Ann Plast Surg 2007; 58(4): 434-440.

43 Birch J, Ross RB, Lindsay WK. The end result of growth and treatment in bilateral complete cleft lip and palate. Panminerva Med 1967; 9: 391-397.

44 Narula JK, Ross RB. Facial growth in children with complete bilateral cleft lip and palate. Cleft Palate J 1970; 7: 239-248. 
45 Pichler H. [Zur operation der doppeltenlippen-gaumenspalten.] Deutsch Z Cir 1926; 195: 104-107. German.

46 Friede $\mathrm{H}$, Johanson B. A follow-up study of cleft children treated with vomer flap as part of a three-stage soft tissue surgical procedure. Facial morphology and denta occlusion. Scand J Plast Reconstr Surg 1977; 11(1): 45-57.

47 Mølsted K, Palmberg A, Dahl E et al. Malocclusion in complete unilateral and bilateral cleft lip and palate. The results of a change in the surgical procedure. Scand J Plast Reconstr Surg Hand Surg 1987; 21(1): 81-85.

48 Leow AM, Lo LJ. Palatoplasty: evolution and controversies. Chang Gung Med J 2008; 31(4): 335-345.

49 Delaire J, Precious D. Avoidance of the use of vomerine mucosa in primary surgical management of velopalatine clefts. Oral Surg Oral Med Oral Pathol 1985; 60(6): 589597.

50 Ross RB. Treatment variables affecting facial growth in complete unilateral cleft lip and palate. Cleft Palate J 1987; 24(1): 5-77.

51 Jackson O, Stransky CA, Jawad AF et al. The Children's Hospital of Philadelphia modification of the Furlow double-opposing Z-palatoplasty: 30-year experience and long-term speech outcomes. Plast Reconstr Surg 2013; 132(3): 613-622.

52 Losee JE, Kirschner RE. Comprehensive cleft care. New York: McGraw-Hill, 2009: 371-390.

53 Chate R, DiBiase D, Ball J et al. A comparison of the dental occlusions from a United Kingdom sample of complete unilateral cleft lip and palate patients with those from the Eurocleft Study. Transactions of the 8th International Congress on Cleft palate and Related Craniofacial Anomalies. Singapore: Stamford Press, Academy of Medicine, 1997: 371 376.

54 Long RE Jr, McNamara JA Jr. Facial growth following pharyngeal flap surgery: skeletal assessment on serial lateral cephalometric radiographs. Am J Orthod 1985; 87(3): 187-196.

55 Voshol IE, van Adrichem LN, van der Wal KG et al. Influence of pharyngeal flap surgery on maxillary outgrowth in cleft patients. Int J Oral Maxillofac Surg 2013; 42(2): 192-197.

56 Heliövaara A, Haapanen ML, Hukki J et al. Long-term effect of pharyngeal flap surgery on craniofacial and nasopharyngeal morphology in patients with cleft palate. Acta Odontol Scand 2003; 61(3): 159-163.

57 Schweckendiek W, Doz P. Primary veloplasty: long-term results without maxillary deformity: a twenty-five year report. Cleft Palate J 1978; 15(3): 268-274.
58 Bardach J, Morris HL, Olin WH. Late results of primary veloplasty: the Marburg Project. Plast Reconstr Surg 1984; 73(2): 207-218.

59 Hotz MM, Gnoinski WM, Nussbaumer $\mathrm{H}$ et al. Early maxillary orthopedics in CLP cases: guidelines for surgery. Cleft Palate J 1978; 15(4): 405-411.

60 Lilja J, Mars M, Elander A et al. Analysis of dental arch relationships in Swedish unilateral cleft lip and palate subjects: 20-year longitudinal consecutive series treated with delayed hard palate closure. Cleft Palate Craniofac J 2006; 43(5): 606-611.

61 Semb G. A study of facial growth in patients with unilateral cleft lip and palate treated by the Oslo CLP Team. Cleft Palate Craniofac J 1991; 28(1): 1-21; discussion 4648

62 Mølsted K, Asher-McDade C, Brattström V et al. A six-center international study of treatment outcome in patients with clefts of the lip and palate: Part 2. Craniofacial form and soft tissue profile. Cleft Palate Craniofac J 1992; 29(5): 398-404.

63 del Guercio F, Meazzini MC, Garattini G et al. A cephalometric intercentre comparison of patients with unilateral cleft lip and palate at 5 and 10 years of age. Eur J Orthod 2010; 32(1): 24-27.

64 Liao YF, Yang IY, Wang R et al. Two-stage palate repair with delayed hard palate closure is related to favorable maxillary growth in unilateral cleft lip and palate. Plast Reconstr Surg 2010; 125(5): 1503-1510.

65 Mommaerts MY, Combes FA, Drake D. The Furlow Z-plasty in two-staged palatal repair modifications and complications. Br J Oral Maxillofac Surg 2006; 44(2): 94-99.

66 Richard B, Russell J, McMahon S et al. Results of randomized controlled trial of soft palate first versus hard palate first repair in unilateral complete cleft lip and palate. Cleft Palate Craniofac J 2006; 43(3): 329-338.

(i) This work is licensed under a Creative Commons AttributionNonCommercial-NoDerivs 3.0 Unported License. The images or other third party material in this article are included in the article's Creative Commons license, unless indicated otherwise in the credit line; if the material is not included under the Creative Commons license, users will need to obtain permission from the license holder to reproduce the material. To view a copy of this license, visit http://creativecommons.org/licenses/ by-nc-nd/3.0 